\title{
Evaluation of Anthocyanin Production in White and Purple Maize (Zea mays L.) Using Methyl Jasmonate, Phosphorus Deficiency and High Concentration of Sucrose
}

\author{
S. Leon-Cisneros ${ }^{1,2, * *}$, A. Quirola-Garcés ${ }^{1,2, * *}$, J. AlvareZ-SAntana $^{1, * *}$, \\ N. Barriga-Medina ${ }^{1,3}$, D. RamireZ-Villacís ${ }^{1,3}$, M. CAViedes ${ }^{1}$, \\ L. RAMIREZ-CÁRDENAS ${ }^{2}$ and A. LEON-REYES ${ }^{1,3,4,5, *}$ \\ ${ }^{1}$ Laboratorio de Biotecnología Agrícola y de Alimentos, Ingeniería en Agronomía, \\ Colegio de Ciencias e Ingenierías, Universidad San Francisco de Quito, Campus Cumbayá, Quito, Ecuador \\ ${ }^{2}$ Ingeniería en Alimentos, Colegio de Ciencias e Ingenierías, \\ Universidad San Francisco de Quito, Campus Cumbayá, Quito, Ecuador \\ ${ }^{3}$ Instituto de Microbiología, Colegio de Ciencias Biológicas y Ambientales \\ COCIBA Universidad San Francisco de Quito USFQ, Campus Cumbayá, Quito, Ecuador \\ ${ }^{4}$ Instituto de Investigaciones Biológicas y Ambientales BIÓSFERA, \\ Colegio de Ciencias Biológicas y Ambientales \\ COCIBA Universidad San Francisco de Quito USFQ, Campus Cumbayá, Quito, Ecuador \\ ${ }^{5}$ Department of Biology, University of North Carolina at Chapel Hill, NC 27599-3280, USA
}

(Received 13 July 2018; Accepted 25 June 2019;

Communicated by I. Molnár)

Anthocyanins are plants metabolites that are recognized by its red/purple coloration produced in flowers, seeds and leaves. These molecules are potentially important to the industry for its antioxidant capacity, disease prevention and as a natural dye. Currently, the production of anthocyanins is carried out using in vitro culture of Vitis vinifera and its yield is increased by using elicitors or stress factors. Zea mays is relevant due to its high content of cyanidin3 - $\beta$-glucoside anthocyanin. In the present study the production of cyanidin-3- $\beta$-glucoside was evaluated with different mechanisms of elicitation using in vivo and in vitro culture of purple and white maize varieties. The highest callus induction $(85 \%)$ for white maize was obtained in MS medium supplemented with $2 \mathrm{mg} / \mathrm{L}$ of 2,4-Dichlorophenoxyacetic acid, while for purple maize (93\%) was obtained in $\mathrm{N} 6$ medium with $2 \mathrm{mg} / \mathrm{L}$ of 2,4-Dichlorophenoxyacetic acid, using germinated seed as explant for both varieties. Methyl jasmonate was evaluated as an elicitation tool, however no cyanidin-3- $\beta$-glucoside was found to be accumulated or produced in vitro. In contrast, using germinated seeds and radicle tissue, elicitation using phosphorus deficiency treatment produced the highest cyanidin-3- $\beta$ glucoside accumulation $\left(0.06 \mathrm{mg} \mathrm{g}^{-1}\right)$ in white maize. No elicitation and further production of anthocyanins was found when purple maize were used using this method. Therefore, in vivo elicitation in white maize is a potential method to produce a stable anthocyanin that could be optimized for future applications.

Keywords: purple maize, callus induction, anthocyanin elicitation, cyanidin-3- $\beta$ glucoside

\footnotetext{
*Corresponding author; E-mail: aleon@usfq.edu.ec
}

$* *$ These authors equally contributed to this work. 


\section{Introduction}

Anthocyanins are phenolic compounds that belong to the flavonoid group (Loreti et al. 2008). They are secondary metabolites of plants that produce the red/purple coloration of flowers, leaves and seeds, and play an important role in the plant protection, pollination and signaling pathways (Guo et al. 2008). In addition to the various functions in plants, anthocyanins have a wide range of benefits in human health (Carvalho et al. 2015). In various industries, anthocyanins have been used as natural dyes to give red, orange and blue color to different products (Gould et al. 2008). They are employed in food industry, since they are easily incorporated into aqueous systems, and they do not generate adverse health concerns with synthetic dyes (Loreti et al. 2008; Silva et al. 2017). Due to these major advantages, there is a worldwide tendency to expand the use and to improve the production of anthocyanin (Silva et al. 2017).

Diverse species of plants have been utilized to produce anthocyanins both in vivo and in vitro systems. However, currently, the production of anthocyanins is preferably carried out in vitro using cells or plant organs (Ananga et al. 2013). In vitro culture works under controlled conditions, which facilities standardization of large scale production, also avoid losses by microbial contaminations or phytopathogens (Silva et al. 2017). On the other hand, the yield of production is limited, which is why several mechanisms have been studied such as variations of culture conditions, addition of precursors and use of growth regulators, stresses factors and elicitors (Silva et al. 2017; Ananga et al. 2013).

Different stress factors were evaluated for anthocyanins production such as application of high concentration of sugar and deficiency of some nutrients in the culture medium (Ananga et al. 2013). The accumulation of anthocyanins after application of high sugar concentrations has been demonstrated to be an efficient method in different plant species like Arabidopsis thaliana and Ceratonia siliqua (Gould et al. 2008; Loreti et al. 2008). The elicitors are molecules which induce the synthesis and accumulation of substances with antimicrobial and anti-stress effects. The use of inducers related to stress responses and activation of defense mechanisms such as jasmonic acid and salicylic acid have been tested to produce anthocyanins in soybean seeds, Arabidopsis seeds, tulip bulbs, peach roots and callus of Daucus carota (Gould et al. 2008; Ananga et al. 2013; Deroles 2009).

The most common plant species select for large scale anthocyanin production is Vitis vinifera. Several studies demonstrated the use of cell culture is very useful and simple system for industrial and research purposes (Deroles 2009). Elicitation leading the production of anthocyanins was evaluated using phytohormones, nutrients, physical conditions and elicitors (Deroles 2009). In contrast, other studies demonstrated that the modification of abiotic and biotic factors in the different tissues such as fruits and flowers can accumulate anthocyanins therefore leading the tissue for extraction of this compound with different methods (Silva et al. 2017).

Enocianine is the most abundant anthocyanin in $V$. vinifera, however, this compound presents a great limitation for downstream processing and storage (Cuevas et al. 2008). As an alternative, maize (Zea mays L.) has aroused great interest as a source of production 
of another type of anthocyanin: cyanidin-3- $\beta$-glucoside, with greater stability for downstream processing and human health (Cuevas et al. 2008; Silva et al. 2017). Given the properties of cyanidin-3- $\beta$-glucoside derived from maize, the aim of the study was to evaluate the production of cyanidin-3- $\beta$-glucoside in vitro and in vivo in two varieties of maize (purple and white) using three elicitation mechanisms: phosphorus deficiency, excess of sucrose and application of methyl jasmonate (MeJA).

\section{Materials and Methods}

\section{Plant material}

White maize seeds (Zea mays L. variety mishka) were obtained from a crop in Nayón, Quito-Ecuador; while purple maize seeds (Zea mays L. variety indurata) were obtained from a collection of seeds grown in El Quinche and Yaruquí, Quito-Ecuador (Fig. S1*).

\section{Callus induction}

Seeds from both varieties were disinfected according to Sauer and Burroughs (1986) with some modifications. Seeds were placed in a desiccator along with a beaker that contained a solution of $3 \mathrm{~mL}$ of $37 \%$ hydrochloric acid and $100 \mathrm{~mL}$ of $5 \%$ sodium hypochlorite. The seeds were left in the closed compartment full of produced gas for 24 hours.

After disinfection, seeds were placed aseptically in $250 \mathrm{~mL}$ glass flask filled with 30 $\mathrm{mL}$ of MS medium (Murashige and Skoog 1962), 3\% (w/v) of sucrose and $15 \mathrm{~g} / \mathrm{L}$ Bactoagar (BA) and $\mathrm{pH}$ were adjusted to 5,8 before autoclaving at $121{ }^{\circ} \mathrm{C}$ for $45 \mathrm{~min}$.

Two sets consisting of 10 flasks each were incubated at room temperature with a 12/12 photoperiod. After one week, germinated seeds with $10-15 \mathrm{~mm}$ long radicle were obtained from the first set of flasks. The second set of flasks were incubated for 4 weeks, after which tip meristems were isolated from seedlings.

For callus induction, germinated seeds and tip meristems were tested in two basal media, MS and N6 (Sauer and Burroughs 1986) both with 3\% (w/v) of sucrose. The media were supplemented with $0,2,3 \mathrm{mg} / \mathrm{L}$ of 2,4-Dichlorophenoxyacetic acid (2,4-D), in solidified medium previously described. Four explants were placed per $250 \mathrm{~mL}$ glass flask filled with $30 \mathrm{~mL}$ of medium for $24 \mathrm{~h}$ continuous light followed by darkness for 3 weeks, at this point callus was used to test the anthocyanin production.

\section{Elicitation of anthocyanins in vitro}

The callus obtained from both varieties of maize were washed with $1 \mathrm{~mL}$ of different concentrations of MeJA $(0,30,100 \mu \mathrm{M})$ ( Loreti et al. 2008; López et al. 2011) and incubated at room temperature with a 12/12 photoperiod. After 7 days, the concentration of anthocyanins was determined by $\mathrm{pH}$ differential method (Puertas et al. 2013).

\footnotetext{
*Further details about the Electronic Supplementary Material (ESM) can be found at the end of the article.
} 


\section{Elicitation of anthocyanins in vivo}

Prior to the seed germination, seeds were washed with a commercial liquid detergent solution for $5 \mathrm{~min}$, rinsed with tap water to remove traces of soap and then placed in a solution of Benomyl $4 \mathrm{~g} / \mathrm{L}+$ Captan $4 \mathrm{~g} / \mathrm{L}$ for $20 \mathrm{~min}$. Finally, they were washed 5 times with distilled water (López et al. 2011).

After washing, 5 seeds per container were placed in $250 \mathrm{ml}$ glass flasks with filter paper and sterile distilled water until the seed was submerged. They were incubated at $20-25^{\circ} \mathrm{C}$ in dark until they reached $30 \mathrm{~mm}$ long root. At this time, three elicitation mechanisms were tested according to López et al. (2011) and Ulrychová and Sosnavá (1970) with modifications: excess sucrose (MS solution supplemented with $60 \mathrm{~g} / \mathrm{L}$ sucrose), phosphorus deficiency (MS solution without addition of phosphorus) and MeJA (3.3, 10, 30 and $100 \mu \mathrm{M}$ MeJA solution). MeJA was diluted first in $70 \%$ ethanol as described by Loreti et al. (2008). All solutions were adjusted to $\mathrm{pH} 5.8$ and no solidifying agent was added. Complementary, two solutions were used as control: basal MS without sucrose and sterile distilled water with the corresponding concentration of ethanol used to dilute MeJA.

To each flask, $1 \mathrm{~mL}$ of the different solutions were added directly to the germinated seeds. The flasks were incubated at room temperature with $12 \mathrm{~h}$ light. After 7 days, the concentration of cyanidin-3- $\beta$-glucoside was determined.

\section{Determination of the concentration}

of cyanidin-3- $\beta$-glucoside by differential $\mathrm{pH}$ method

To quantify cyanidin-3- $\beta$-glucoside concentration from callus (in vitro) and germinated seed (in vivo), 0.3 grams of the radicle was taken and macerated in a mortar with liquid nitrogen until powder was obtained, then $3 \mathrm{~mL}$ of acidified methanol (proportion 1:99 with $37 \% \mathrm{HCl}: 98 \%$ methanol) was added and homogenized. The mixture was kept in the dark for 24 hours at $4{ }^{\circ} \mathrm{C}$. Two aliquots of $1 \mathrm{~mL}$ were taken and $4 \mathrm{~mL}$ of potassium chloride buffer $\mathrm{pH} 1(0.025 \mathrm{M})$ were added to the first aliquot, and $4 \mathrm{~mL}$ of sodium acetate buffer $\mathrm{pH} 4.5(0.4 \mathrm{M})$ was added to the second aliquot. The absorbance of each aliquot was measured at $530 \mathrm{~nm}$ and $700 \mathrm{~nm}$ using distilled water as a blank (Puertas et al. 2013).

\section{Experimental design and statistical analysis}

For callus induction, a Completely Randomized Design with a factorial arrangement $2 \times 2 \times 3$ was used for the two maize varieties with three repetitions per treatment; giving a total of 36 experimental units. The factors used were: explant type (germinated seed and meristem), culture media (N6 and MS), and 2,4-D hormone concentration $(0 \mathrm{mg} / \mathrm{L}$, $2 \mathrm{mg} / \mathrm{L}$ and $3 \mathrm{mg} / \mathrm{L}$ ). The percentage of callus induced per vessel was evaluated.

For anthocyanin elicitation in vitro, 6 treatments were obtained in a randomized experimental design with three replicates per treatment; giving a total of 18 experimental units. For in vivo experiments, 16 treatments were obtained arranged in a randomized 
experimental design with three replicates per treatment; giving a total of 48 experimental units. The concentration of cyanidin-3- $\beta$-glucoside $(\mathrm{mg} / \mathrm{g}$ fresh weight) was quantified by $\mathrm{pH}$ differential method.

The data were analyzed using Analysis of Variance (ANOVA) and the differences between treatments were evaluated by the Tukey test at 5\% using R studio (RStudio Team 2015).

\section{Results}

\section{Callus induction of maize}

Callus induction was successful for both maize varieties, however, the addition of 2,4-D had the most significant effect on callus development regardless explant type or medium (Fig. 1). The percentage of callus induction in white maize ranged from 8 to $83 \%$. Germinated seeds in MS medium supplemented with $2 \mathrm{mg} / \mathrm{L}$ of 2,4-D was the treatment with the greatest percentage of callus development (83\%). In the purple maize, callus induction ranged from 8 to $93 \%$, yet the best treatment (93\%) was when used germinated seed as explants in N6 medium, supplemented with $2 \mathrm{mg} / \mathrm{L}$ of 2,4-D (Fig. 1). Callus obtained from the best treatments from each variety was used for further experiments.

\section{Elicitation of anthocyanins in maize using callus cells (in vitro)}

After obtaining callus from each maize variety, (MeJA) was used to trigger anthocyanins production. After 7 days of MeJA application at two different concentrations $(30 \mu \mathrm{M}$, $100 \mu \mathrm{M}$ ) was not possible to perceive any red/purple coloration in the callus (Fig. S2),

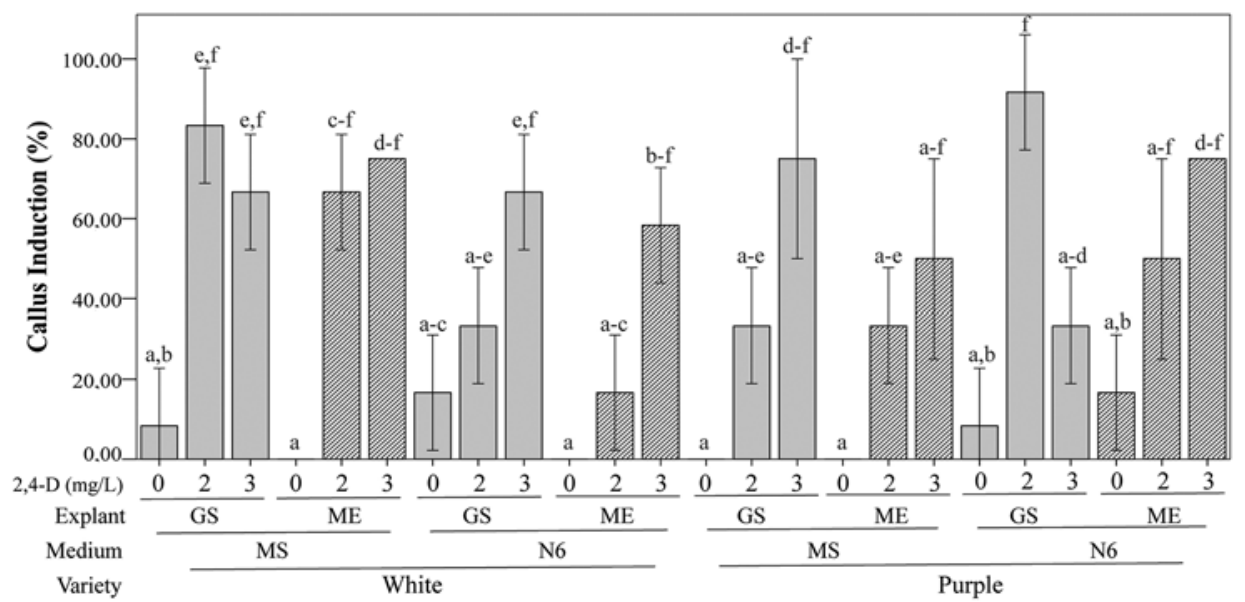

Figure 1. Callus development using white and purple maize varieties under a range of 2,4-D concentrations $(0,2,3 \mathrm{mg} / \mathrm{L})$, explant type (GS: germinated seed, ME: tip meristem) and culture media (MS: Murashige and Skoog, N6). Means followed by the same letters do not differ from each other by ANOVA with 5\% probability Tukey test. Error bars show standard deviation 

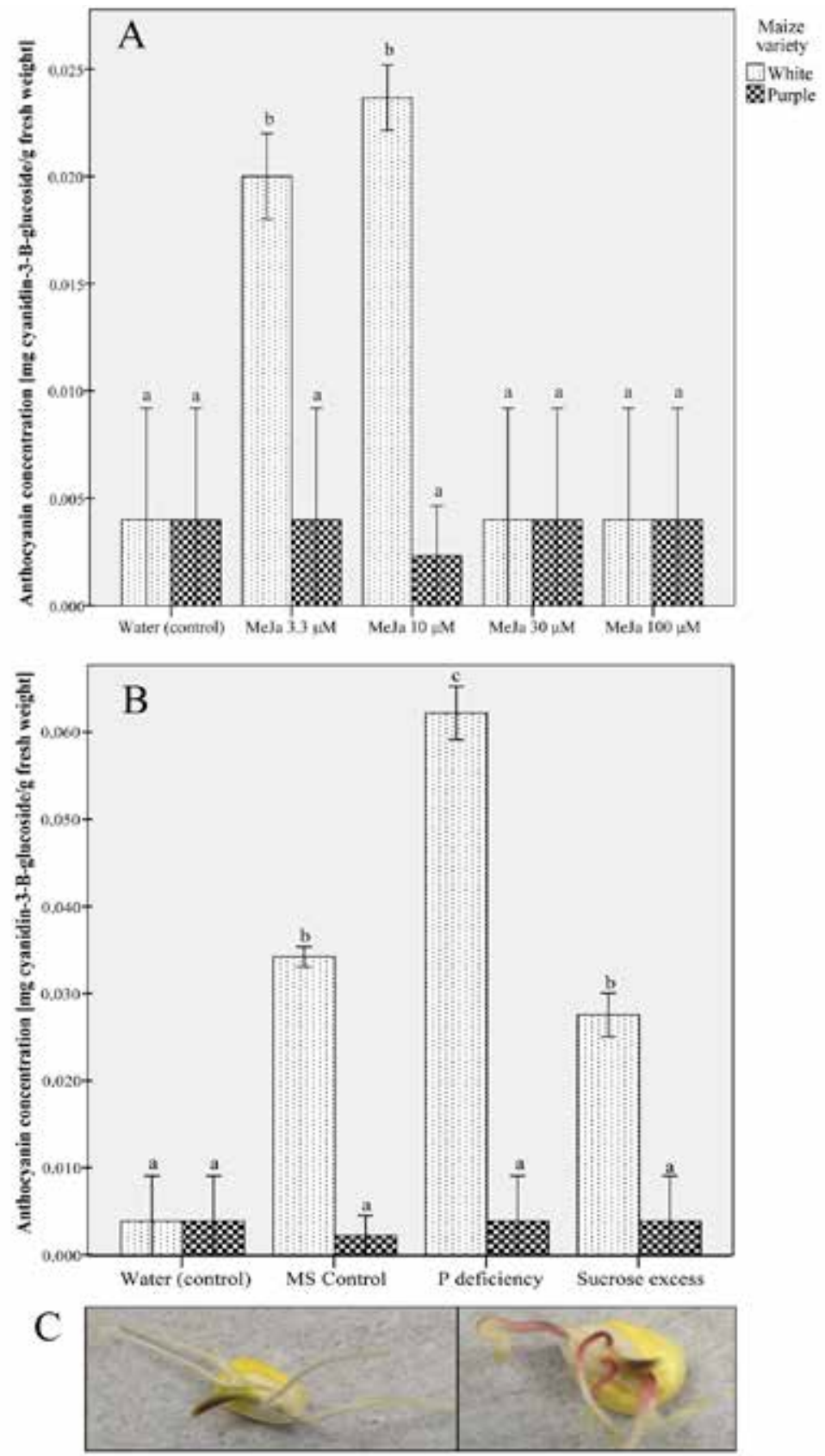

Figure 2. In vivo elicitation of cyanidin-3- $\beta$-glucoside in white maize and purple maize. A - Different methyl jasmonate (MeJA) concentrations. B - MS medium, excess of sucrose and phosphorus deficiency. Means followed by the same letters do not differ from each other by ANOVA with 5\% probability Tukey test. Error bars show standard deviation. C - Left panel: MS medium control, right panel: MS treatment with phosphorus deficiency. Radicle showed changes in coloration 
which is the first indication of anthocyanin accumulation (Deroles 2009). To confirm this observation, the concentration of cyanidin-3- $\beta$-glucoside was quantified by $\mathrm{pH}$ differential method, yet, the production of this anthocyanin could not be detected (Table S1).

\section{Elicitation of anthocyanins using germinated seed (in vivo)}

Since no elicitation of anthocyanins was generated in callus cells during in vitro culture, the effect of elicitation was evaluated using intact tissue (in vivo). Here, germinated seeds from purple and white maize were tested with MeJA, excess of sucrose and phosphorus deficiency as a general elicitor of anthocyanins.

As a result, using MeJA as a general inductor there was a statistically significant difference in the production of cyanidin-3- $\beta$-glucoside between the two varieties versus elicitation treatment (Fig. 2A). First, the purple variety had almost no production of cyanidin-3- $\beta$-glucoside (below $0.005 \mathrm{mg} / \mathrm{g}$ fresh weight) for all treatments tested. In contrast, the white variety showed up to $0.025 \mathrm{mg}$ cyanidin-3- $\beta$-glucoside $/ \mathrm{g}$ fresh weight produced after $10 \mu \mathrm{M}$ of MeJA compared to basal concentration of water control that reached $0.005 \mathrm{mg} / \mathrm{g}$ of fresh weight (Fig. 2A).

In contrast, using excess of sucrose and phosphorus deficiency as a specific elicitor the purple variety had almost no production of cyanidin-3- $\beta$-glucoside (below $0.005 \mathrm{mg} / \mathrm{g}$ fresh weight) for all treatments tested. In contrast, the white variety showed up to 0.065 mg cyanidin-3- $\beta$-glucoside $/ \mathrm{g}$ fresh weight and $0.027 \mathrm{mg} / \mathrm{g}$ of fresh weight produced after phosphorus deficiency and excess of sucrose, respectively, compared to MS control that reached $0.035 \mathrm{mg} / \mathrm{g}$ of fresh weight (Fig. 2B). The highest accumulation reached using phosphorus deficiency in the white maize was also evidenced visually, due to the red/ purple color change in roots and shoots when germinated seed were used (Fig. 2C).

Moreover, in white maize, all elicitation treatments tested were effective and produce more anthocyanins when MS was used as basal medium compared to water control (Fig. 2). Further in white maize, MeJA treatments showed a significant increase of anthocyanins production at 3.3 and $10 \mu \mathrm{M}$ treatment and had no effect when tested at $30 \mu \mathrm{M}$ in comparison with water control. As mentioned before, no production of anthocyanins was detected in purple maize.

\section{Discussion}

\section{Callus induction}

In both varieties of maize, the highest percentage of callus was obtained using germinated seed (mature embryos) in media supplemented with $2 \mathrm{mg} / \mathrm{L}$ of 2,4-D. These results agree that embryos regenerates callus more efficiently than other types of explants (Çabuk and Özgen 2016).

The maize varieties showed differences in response to callus formation using different medium, since white maize obtained $83 \%$ of callus supplemented with MS medium + $2 \mathrm{mg} / \mathrm{L} 2,4-\mathrm{D}$, and $93 \%$ of callus in the purple maize cultivated in $\mathrm{N} 6$ medium $+2 \mathrm{mg} / \mathrm{L}$ 
2,4-D (Fig. 1). The concentration of 2,4-D used for callus induction are comparable with previous reports where the optimum concentration was determined using MS medium + $2 \mathrm{mg} / \mathrm{L}$ of 2,4-D (Çabuk and Özgen 2016).

In other study demonstrated similar callogenesis development, since the frequency of callus induction ranged from 26.1 to $84 \%$ in MS medium $+1 \mathrm{mg} / \mathrm{L} \mathrm{2,4-D}$ and using N6 medium $+2 \mathrm{mg} / \mathrm{L} 2,4-\mathrm{D}$ ranged from 38.1 to $85 \%$ (Gorji et al. 2011). The concentration of 2,4-D is an important factor since higher concentration than $4 \mathrm{mg} / \mathrm{L}$ callus induction can be inhibited (Gorji et al. 2011).

In the two varieties of maize was observed that when 2,4-D was not applied, a low percentage of callus formation $(6.25 \%)$ was obtained. This can be explained due to the presence of cytokinin and auxin at the endogenous level in the meristems or in the germinated seed that allow cell de-differentiation and proliferation (Matos and Sánchez 2011).

The variation observed between the two varieties can be explained due genotypic differences since it is an important factor for callus formation and plant regeneration (Gorji et al. 2011; Torres et al. 2012). Thus, the response of callus induction is largely based on concentrations of 2,4-D and their interaction with the maize variety (Shohael et al. 2003). These are the reasons why a difference could be observed in obtaining callus in the two types of maize used for this research, each of the varieties have their optimal conditions (medium and hormone dose) for callus regeneration.

\section{Anthocyanin elicitation}

Different elicitation mechanism was evaluated for cyanidin-3- $\beta$-glucoside production in two varieties of maize using in vitro and in vivo systems. The use of $30 \mu \mathrm{M}$ and $100 \mu \mathrm{M}$ MeJa in vitro did not produced cyanidin-3- $\beta$-glucoside (Fig. S2). The absence of anthocyanins production in these treatments could be dependent by antagonisms and tissue dependent. Previously, it has been reported antagonistic effects auxins (2,4-D) on the biosynthesis and inhibition of anthocyanin production in Daucus carota and in callus of Haplopappus gracilis (Ozeki and Komamime 1986; Stickland and Sunderland 1971). Since in our assays 2,4-D remained in the basal medium for callus maintains, this auxin mediated inhibition of MeJA induce anthocyanins production could be occurring. Also, the lack of anthocyanin accumulation could be attributed to the callus state (Fehér et al. 2003) and MeJA concentrations evaluated could cause an inhibition in anthocyanin production (Fang et al. 1999).

It has been demonstrated that the accumulation of anthocyanin could be triggered by biotic and abiotic factors in flowers and fruits (Silva et al. 2017), however there are not enough information about elicitation of anthocyanin in vivo in Zea mays L. (Gould et al. 2008). Additionally, exists a great interest to develop methods with high extraction yields of anthocyanin in vivo (Silva et al. 2017). In the present study, it was demonstrated that the accumulation of anthocyanin in vivo using different elicitation mechanisms showed the production of anthocyanins and accumulation of red/purple color in germinated white maize seeds (Fig. 2). 
White maize accumulates more anthocyanin than purple maize under all treatments. The purple maize variety presented accumulation of anthocyanin in the pericarp of mature seeds (Torres et al. 2012) but in the present study, the accumulation of cyanidin-3- $\beta$ glucoside was evaluated in the radicle (germinated seed), so anthocyanin production could not be detected. Thus, it demonstrates that depending on the maize variety, plant tissue and elicitation mechanism could lead to different results, being an interesting field of research (Loreti et al. 2008).

The accumulation of cyanidin-3- $\beta$-glucoside differed according to the elicitation mechanism (Fig. 2), the treatment of phosphorus deficiency in white maize seeds showed the highest concentration ( $0.062 \mathrm{mg}$ cyanidin-3- $\beta$-glucoside/g fresh weight) in comparison to the MS control and the other treatments. In a study conducted in Lens culinaris under conditions of phosphorus deficiency, it was possible to obtain $0.3 \mathrm{mg}$ of phenolic compounds/g fresh weight (Sarker and Karmoker 2011). Therefore, absence of phosphorus in the culture media influenced the phenolic content in the tissue.

On the other hand, in the treatment with the excess of sucrose with a concentration of $0.027 \mathrm{mg}$ cyanidin-3- $\beta$-glucoside/fresh weight was obtained, which was not statistically different in relation to the MS control which obtained $0.035 \mathrm{mg} / \mathrm{g}$ fresh weight (Fig. 2B). There are reports in $V$. vinifera that such accumulation of anthocyanins can be explained as a function of the osmotic stress that can be generated (Miñaño et al. 2004). Therefore, the stimulation of anthocyanin production presented a proportional increase in relation to the osmolarity present by the medium.

In Figure 2, it is shown that there was no significant difference between the excess sucrose treatment and MS control. MS control contains nitrates and ammonia at $60 \mathrm{mM}$, this concentration could be considered high and therefore the influence of salts can be determinant for the elicitation of anthocyanins in plants (Guo et al. 2008).

In the case of the different concentrations of MeJA (Figure 2A), a maximum accumulation of cyanidin-3- $\beta$-glucoside/g fresh weight was found in the treatments of 3.3 and $10 \mu \mathrm{M}$ and in higher concentrations produce an inhibitory effect. In a study of maize performed by Kim et al. (2006), it has been shown that at low concentrations of MeJA $(3.3 \mu \mathrm{M}$ and $10 \mu \mathrm{M})$ has an induction of $51.8 \%$ of anthocyanins than in higher concentrations of MeJA higher than $10 \mu \mathrm{M}$. However, in the study of Shimizu et al. (2010) with Gynura bicolor, there is a greater accumulation at concentrations between $25 \mu \mathrm{M}$ to $50 \mu \mathrm{M}$ of MeJA. The response after methyl jasmonate application that further induces the production of cyanidin-3- $\beta$-glucoside may be due to the difference of the genetic background among plant species.

In summary, it is demonstrated that the elicitation of anthocyanins in germinated seeds (radicle) of the white variety produces a greater accumulation of cyanidin-3- $\beta$-glucoside in comparison with the purple variety. Additionally, the best elicitation mechanism was the treatment with phosphorus deficiency reaching a concentration of cyanidin-3- $\beta$ glucoside of $0.062 \mathrm{mg} / \mathrm{g}$ fresh weight. Furthermore, the addition of the MS medium generated an additional elicitation ( $0.038 \mathrm{mg}$ cyanidin-3- $\beta$-glucoside $/ \mathrm{g}$ fresh weight) without the need of stress. It is important to investigate the combination of these mechanisms in vivo to achieve better production and further implementation for industries purposes. 


\section{Acknowledgements}

\section{This work was funded by Chancellor Grants USFQ and Poli Grants USFQ.}

\section{References}

Ananga, A., Georgiev, V., Ochieng, J., Phills, B., Tsolova, V. 2013. Production of anthocyanins in grape cell cultures: a potential source of raw material for pharmaceutical, food, and cosmetic industries. In Poljuha, D., Sladonja, B. (eds), The Mediterranean Genetic Code-Grapevine and Olive. InTechOpen. Rjeka, Croatia. pp. 247-287.

Carvalho, F., Gutierres, J., Bohnert, M., Zago, A., Abdalla, F., Vieira, J., Palma, H., Oliveira, S., Spanevello, R., Duarte, M., Lopes, S., Aiello, G., Amaral, M., Pippi, N., Andrade, C. 2015. Anthocyanins suppress the secretion of proinflammatory mediators and oxidative stress, and restore ion pump activities in demyelination. J. Nutr. Biochem. 26:378-390.

Cuevas, M., Antezana, A., Winterhalter, P. 2008. Análisis y caracterización de antocianinas en diferentes variedades de maíz (Zea Mays) Boliviano. Memorias Red-Alfa Lagrotech. Comunidad Europea. Cartagena, Colombia: 79-95.

Çabuk, B., Özgen, M. 2016. The effect of different 2,4-D doses on callus induction and chromosomal structure in maize (Zea Mays L.). IJOEAR 2:188-194.

Deroles, S. 2009. Anthocyanin biosynthesis in plant cell cultures: a potential source of natural colourants. In Gould, K., Davies, K., Winfield, C. (eds), Anthocyanins Byosynthesis, Functions and Application. Springer. New York, United States of America. pp. 107-154.

Fang, Y., Smith, A., Pépin, M. 1999. Effects of exogenous methyl jasmonate in elicited anthocyanin producing cell cultures of Ohelo (Vaccinium pahalae). In Vitro Cell Dev. Biol. Plant 35:106-113.

Fehér, A., Pasternak, T., Dudits, D. 2003. Transition of somatic plant cells an embryogenic state. Plant Cell Tiss. Org. 74:201-228.

Gorji, A., Zolnoori, M., Jamasbi, A., Zolnoori, Z. 2011. In vitro plant generation of tropical maize genotypes. In International Conference on Environmental, Biomedical and Biotechnology.IACSIT Press. Singapoore. pp. 52-59.

Gould, K., Davies, K., Winefield, C. 2008. Anthocyanin: Biosynthesis, Functions and Applications. Springer. New York.

Guo, J., Han, W., Wang, M. 2008. Ultraviolet and environmental stresses involved in the induction and regulation of anthocyanin biosynthesis: A review. Afr. J. Biotechnol. 7:4966-4972.

Kim, J., Lee, B., Kim, S., Oh, K., Cho, K. 2006. Responses to environmental and chemical signals for anthocyanin biosynthesis in non-chlorophyllous corn (Zea mays L.) leaf. J. Plant Biol. 49:16-25.

Loreti, E., Povero, G., Novi, G., Solfanelli, C., Alpi, A., Perata, P. 2008. Gibberellins, jasmonate and abscisic acid modulate the sucrose-induced expression of anthocyanin biosynthetic genes in Arabidopsis. New Phytol. 179:1004-1016.

López, A., Montalvo, E., Andrade, I., Gómez, J. 2011. Inducción de antocianinas y compuestos fenólicos en cultivos celulares de jamaica (Hibiscus sabdariffa L.) in vitro. Rev. Chapingo Ser. Hortic. 17:77-87.

Matos, A., Sánchez, A. 2011. Evaluación de reguladores de crecimiento para la inducción de callo en Aloe vera L. Multiciencias 11:7-14.

Miñaño, A., Chico, J., López, E., Sisniegas, M., Bobadilla, M. 2004. Efecto de la concentración de sacarosa en la producción de antocianinas a partir de cultivos celulares de Vitis vinifera L var. redglove. Rev. Peru Biol. 11:187-192.

Murashige, T., Skoog, F. 1962. A revised medium for rapid growth and bioessays with tobacco tissue culture. Physiol. Plantarum 15:473-497.

Ozeki, Y., Komamine, A. 1986. Effects of growth regulators on the induction of anthocyanin synthesis in carrot suspension cultures. Plant Cell Physiol. 27:1361-1368. 
Puertas, M., Ríos, Y., Alberto, C. 2013. Determinación de antocianinas mediante extracción asistida por radiación de microondas en frijol (Phaseolus vulgaris L.) de alto consumo en Antoquia-Colombia. Rev. Cubana Plant Med. 18:288-297.

RStudio Team. 2015. RStudio: Integrated Development for R. RStudio, Inc., Boston, MA.

Sarker, B., Karmoker, J. 2011. Effects of phosphorus deficiency on accumulation of biochemical compounds in Lentil (Lens culinaris medik). Bangladesh J. Botany 40:23-27.

Sauer, D., Burroughs, R. 1986. Disinfection of seed surfaces with sodium hypochlorite. Phytopathology 76:745-749.

Shimizu, Y., Maeda, K., Kato, M., Shimomura, K. 2010. Methyl jasmonate induces anthocyanin accumulation in Gynura bicolor cultured roots. In Vitro Cell Dev. Biol. Plant 46:460-465.

Shohael, A., Akanda, M., Parvaez, S., Mahfuja, S., Alam, M., Islam, R., Joarder, S. 2003. Somatic embryogenesis a plant regeneration from immature embryo derived callus of inbred maize (Zea mays L.). Biotechnology 2:154-161.

Silva, S., Costa, E., Calhau, C., Morais, R., Pintado, M. 2017. Anthocyanin extraction from plant tissue: A review. Crit. Rev. Food Sci. 57:3072-3083.

Stickland, R.G., Sunderland, N. 1971. Production of anthocyanins flavonols and chlorogenic acid by cultured callus tissues of Haplopappus gracilis. Ann. Bot.-London 36:443-457.

Torres, M., Bravo, A., Caviedes, M., Arahana, V. 2012. Molecular and morphological characterization of S2 lines of black corn (Zea mays L.) from Ecuadorian Andes. ACI 4:B11-B18.

Ulrychová, M., Sosnavá, V. 1970. Effect of phosphorus deficiency on anthocyanin content in tomato plants. Biol. Plantarum 12:231-235.

\section{Electronic Supplementary Material (ESM)}

Electronic Supplementary Material (ESM) associated with this article can be found at the website of CRC at http://www.akademiai.com/content/120427/

Electronic Supplementary Table S1. Anthocyanin elicitation in vitro in maize callus using different concentrations of methyl jasmonate

Electronic Supplementary Figure S1. Purple (left) and white (right) maize seeds

Electronic Supplementary Figure S2. Maize callus treated with different concentrations of methyl jasmonate (in vitro test). $a$ - purple maize callus in $30 \mu \mathrm{M} ; b$ - purple maize callus in $100 \mu \mathrm{M} ; c$ - white maize callus in $30 \mu \mathrm{M} ; d$ - white maize callus in $100 \mu \mathrm{M}$ 